\title{
The proatherogenic cytokine interleukin-18 is secreted by human adipocytes
}

\author{
Thomas Skurk, Hubert Kolb ${ }^{1}$, Sylvia Müller-Scholze ${ }^{1}$, Karin Röhrig ${ }^{1}$, Hans Hauner and Christian Herder ${ }^{1}$ \\ Else Kröner-Fresenius Center for Nutritional Medicine, Technical University Munich, D-85350 Weihenstephan, Germany and ${ }^{1}$ German Diabetes Clinic, \\ German Diabetes Center, Leibniz Center at the Heinrich-Heine-University, Auf'm Hennekamp 65, D-40225 Düsseldorf, Germany
}

(Correspondence should be addressed to C Herder; Email: Christian.Herder@ddz.uni-duesseldorf.de)

\begin{abstract}
Objective: Interleukin (IL)-18, an important mediator of innate immunity and strong risk factor for the development of cardiovascular disease, was shown recently to be elevated in obesity. The aim of our study was to investigate whether human adipocytes produce IL-18.

Methods: Human adipose tissue was obtained from lean women undergoing elective plastic surgery and from obese individuals undergoing laparoscopic surgery (gastric banding). Preadipocytes from mammary adipose tissue were isolated and differentiated under defined adipogenic conditions. IL-18 expression was analyzed by real-time reverse transcriptase PCR, ELISA and immunocytochemistry. Results: Human preadipocytes of all differentiation stages spontaneously secreted IL-18. In parallel significant amounts of IL-18 mRNA were detected. Freshly isolated mature adipocytes from subcutaneous and omental depots also released IL-18. IL-18 release from adipocytes from obese donors was about 3fold higher compared to adipocytes from non-obese donors.

Conclusions: We conclude that human adipose tissue produces IL-18 and thereby contributes to systemic IL-18 concentrations. This finding supports the concepts that adipocytes behave as primitive immune cells and that IL-18 may mediate some of the detrimental complications of obesity such as cardiovascular disease and type 2 diabetes.
\end{abstract}

European Journal of Endocrinology 152 863-868

\section{Introduction}

Interleukin (IL)-18 was identified and classified as a member of the proinflammatory IL-1 family (1). IL-18, originally described as the interferon $\gamma$-inducing factor (IGIF), was cloned by us from the pancreas of animals with autoimmune type 1-like diabetes (2). Subsequently, a regulatory role of IL-18 in islet inflammation was demonstrated (3). Overproduction of IL-18 is known to induce severe inflammatory disorders (4). In general, IL-18 enhances the IL-12-driven T helper (Th) 1 immune response, but IL-18 is also able to stimulate Th2 immune responses in the absence of IL-12 (4-6). Several lines of evidence indicated recently that IL-18 is also involved in atherosclerosis. An elevated concentration of systemic IL-18 has been reported to be a strong predictor of cardiovascular death in a prospective study with patients with documented coronary artery disease (7). IL-18 is also highly expressed in atherosclerotic plaques and seems to be a major factor in plaque destabilization (8). Importantly, levels of the proatherogenic cytokine IL-18 are known to be elevated in obesity $(9,10)$, which represents a key risk factor for the development of cardiovascular disease $(11,12)$. Obesity is accompanied by low-grade systemic inflammation, and it is probable that some of the circulating inflammatory mediators are released from obese fat tissue, from adipocytes and/or from macrophages within obese fat tissue (13-15). The relevance of obesity and body fat mass for systemic immune-mediator concentrations is supported by observations that weight loss attributable to alterations in diet and/or physical activity as well as liposuction decreased systemic and local cytokine concentrations in adipose tissue (16-18). Weight loss also caused a decrease of systemic IL-18 concentrations $(9,10)$. This finding led us to investigate in the current study whether human adipocytes produce and secrete IL-18. Because of its central role in regulating innate immunity (4), IL-18 could be a key mediator of subclinical inflammation associated with abdominal obesity and in particular represent a link between obesity and the increased risk of developing cardiovascular disease.

\section{Subjects and methods}

\section{Subjects}

Adipose tissue samples were obtained from mammary adipose tissue of lean to slightly overweight adult females (age $<40$ years, body mass index (BMI) 
$<27 \mathrm{~kg} / \mathrm{m}^{2}$ ) undergoing elective mammary reduction and from obese men and women undergoing laparoscopic surgery (gastric banding; age range 33-65 years, BMI $\geq 30 \mathrm{~kg} / \mathrm{m}^{2}$ ). All patients were otherwise healthy; in particular they were free of metabolic or endocrine diseases as assessed by routine clinical examination and laboratory tests. The procedure for obtaining human adipose tissue has been approved by the Ethical Committee of the Heinrich-Heine-University Düsseldorf.

\section{Cell culture}

Stromal cells from human adipose tissue were prepared as described previously (19). Briefly, after removing all fibrous material, gland tissue and visible blood vessels, adipose tissue samples were cut into pieces of $10-20 \mathrm{mg}$ and digested in $10 \mathrm{mM}$ PBS, $200 \mathrm{U} / \mathrm{ml}$ crude collagenase (Biochrom, Berlin, Germany) and $20 \mathrm{mg} / \mathrm{ml}$ BSA (Sigma, Munich, Germany), pH 7.4, for $60 \mathrm{~min}$ at $37^{\circ} \mathrm{C}$ in a shaking water bath. After centrifugation at $200 \boldsymbol{g}$ for collection of disaggregated cells, supernatant with the adipocytes was aspirated and discarded or used for other experiments. Sedimented cells were purged of contaminating red blood cells, filtered through a $150 \mu \mathrm{m}$ nylon mesh (VWR International, Darmstadt, Germany) and washed twice. The sedimented cells were resuspended in Dulbecco's modified Eagle's/Ham's F-12 medium (DMEM/F-12 medium; $\mathrm{v} / \mathrm{v}, 1: 1$ ) supplemented with $10 \%$ fetal calf serum (Biochrom) and inoculated into culture dishes $(6.5 \mathrm{~cm}$; Corning, Wiesbaden, Germany) at a density of approximately $(3-5) \times 10^{4} / \mathrm{cm}^{2}$. After a 16-h incubation for cell attachment, cells were washed twice with PBS and refed with serum-free DMEM/F-12 medium supplemented with $15 \mathrm{mM} \mathrm{NaHCO}_{3}, 15 \mathrm{mM}$ Hepes, $33 \mu \mathrm{M}$ biotin (Sigma), $17 \mu \mathrm{M}$ pantothenate (Sigma), $10 \mathrm{mg} / \mathrm{ml}$ human transferrin (Sigma) and $0.1 \mathrm{mg} / \mathrm{ml}$ gentamycin (Life Technologies, Gaithersburg, MD, USA). To induce adipose differentiation, cells were exposed to $66 \mathrm{nM}$ human insulin (Aventis Pharma, Frankfurt, Germany), $100 \mathrm{nM}$ cortisol (Aventis Pharma), $0.2 \mathrm{nM}$ tri-iodothyronine ( $\mathrm{T}_{3} ; \quad$ Sigma), $1 \mu \mathrm{g} / \mathrm{ml}$ troglitazone (Sankyo Europe, Düsseldorf, Germany) and $0.5 \mathrm{mM}$ 3-isobutyl-1-methylxanthine (IBMX; Serva, Heidelberg, Germany) for the first 4 days. The medium was changed every other day.

In parallel, mature adipocytes were isolated. Since mature adipocytes are very fragile, a shorter collagenase digestion for only $45 \mathrm{~min}$ at $37^{\circ} \mathrm{C}$ in KrebsRinger phosphate buffer (KRP; pH 7.4) with 4\% BSA was applied. Cells were centrifuged $(10 \mathrm{~min}, 200 \boldsymbol{g})$, washed twice with $\mathrm{KRP} / 0.1 \% \mathrm{BSA}$ and filtered twice through a $250 \mu \mathrm{m}$ nylon mesh (VWR International). Adipocytes were allowed to recover from preparation for $24 \mathrm{~h}$ in $\mathrm{KRP} / 0.25 \% \mathrm{BSA}$. After $24 \mathrm{~h}$ medium was renewed and $400 \mu \mathrm{l}$ packed adipocytes were incubated in $4 \mathrm{ml} \mathrm{KRP} / 0.25 \% \mathrm{BSA}$ for $24 \mathrm{~h}$.

\section{Gene expression analysis by real-time reverse transcriptase PCR}

Total RNA of the cultured adipocytes (days 4-16 of culture) was isolated according to the PAXgene Blood RNA protocol (Qiagen, Hilden, Germany) and transcribed with Omniscript reverse transcriptase according to the manufacturer's instructions (Qiagen). Geneexpression analysis was performed using the ABI 7700 sequence detection system (PE Applied Biosystems). Amplification products were measured based on SYBR Green fluorescence (Qiagen). The primers used (MWG-Biotech, Ebersberg, Germany) were 5'GGC AGG AGA ATC ACT TGC ACT-3' (forward) and 5'-AGA GCG CAA TGG TGC AAT C-3' (reverse), amplifying a 67 bp product of human IL-18 (GenBank accession number NM_001562). Glyceraldehyde-3phosphate dehydrogenase (GAPDH) was used as an internal standard to normalize for the relative abundance of IL-18 transcripts. The primer sequences for GAPDH were $5^{\prime}$-CCT CTG ACT TCA ACA GCG ACA C$3^{\prime}$ (forward) and 5'-AGC TTG ACA AAG TGG TCG TTG AG-3' (reverse), amplifying a 82 bp product (GenBank accession number M33197). Amplification was performed over 40 cycles (initial activation step, $15 \mathrm{~min}$ at $95^{\circ} \mathrm{C}$; followed by 40 cycles of denaturation for $30 \mathrm{~s}$ at $95^{\circ} \mathrm{C}$, annealing for $30 \mathrm{~s}$ at $55^{\circ} \mathrm{C}$ and extension for $45 \mathrm{~s}$ at $72^{\circ} \mathrm{C}$ ). To get optimal results (cycle threshold number, $\mathrm{C}_{\mathrm{T}}$, between 20 and 30) we used 2.5 and $100 \mathrm{ng}$ cDNA in the GAPDH and IL-18 assays, respectively.

\section{IL-18 determination}

IL-18 protein was detected by sandwich ELISA (MBL, Nagoya, Japan) according to the manufacturer's instructions, but with incubation of standards and samples for $15-18 \mathrm{~h}$ to increase sensitivity.

\section{Immunocytochemistry}

Cells cultured on glass slides were washed with PBS, fixed with $80 \%$ methanol $/ 20 \%$ acetone $(\mathrm{v} / \mathrm{v})$ for $1 \mathrm{~h}$ at $-20^{\circ} \mathrm{C}$ and washed with Tris-buffered saline $(8 \%$ $\mathrm{NaCl}$ and $2.4 \%$ Tris base, pH 7.6). IL-18 was detected with a monoclonal mouse anti-human IL-18 antibody (\#D044-3; MBL) and the horseradish peroxidase-diaminobenzidine (HRP-DAB) system (R\&D Systems, Minneapolis, MN, USA).

\section{Measurement of glycerol-3-phosphate dehydrogenase (GPDH) activity}

GPDH activity was assessed as a marker of adipose differentiation according to an established method (20). Cells were washed twice in PBS and harvested in a Tris buffer $(0.05 \mathrm{M}$ Tris/HCl, $1 \mathrm{mM}$ EDTA and $1 \mathrm{mM}$ mercaptoethanol, pH 7.4). After complete cell 
lysis by sonification and subsequent centrifugation, GPDH activity was assessed spectrophotometrically after addition of NADH and dihydroxyacetone phosphate (DHAP) (Sigma). For protein determination an established method according to Lowry (21), including protein precipitation with trichloroacetic acid, was used. Specific activity was calculated and expressed by $\mathrm{mU} / \mathrm{mg}$ protein.

\section{Statistical analysis}

Results are expressed as means \pm S.D. from three independent experiments in triplicates. For comparison ANOVA or $t$-test were used as indicated. $P<0.05$ was considered to be statistically significant.

\section{Results}

\section{IL-18 protein production in cultured preadipocytes and freshly isolated human adipocytes}

In the first set of experiments, the IL-18 secretion of cultured or freshly isolated human adipocytes was investigated. To characterize the maturation stage of preadipocytes, GPDH activity was determined. There was a significant increase in GPDH activity over the culture period of 12 days, indicating differentiation from pre- to mature adipocytes from mammary adipose tissue (Fig. 1A). Mammary preadipocytes cultured in non-differentiating conditions (i.e. without troglitazone and IBMX) secreted IL-18 protein spontaneously without significant change during the culture period of 16 days (Fig. 1B). In the presence of troglitazone and IBMX, i.e. under culture conditions favoring adipocyte maturation, IL-18 secretion increased significantly with peak concentrations of $8.8 \pm 4.1 \mathrm{pg} / \mathrm{ml}$ at day 12 (Fig. 1C). Freshly isolated adipocytes from subcutaneous and omental depots from both male and female donors also released IL-18 which was found in culture supernatants at levels of $3.2 \pm 2.9$ and $8.6 \pm 4.7 \mathrm{pg} / \mathrm{ml}$, respectively (Fig. 1D). Both subcutaneous and omental adipocytes were available from four different donors. For these donors, IL-18 accumulation did not differ significantly between the depots. IL-18 concentrations in cultures of subcutaneous adipocytes from obese donors (BMI $\geq 30 \mathrm{~kg} / \mathrm{m}^{2}$ ) reached $5.5 \pm 4.2 \mathrm{pg} / \mathrm{ml}$ and were higher than IL-18 concentrations in adipocyte cultures from non-obese donors with a BMI of $<30 \mathrm{~kg} / \mathrm{m}^{2}$ $(1.8 \pm 0.9 \mathrm{pg} / \mathrm{ml})$. However, the difference was not statistically significant $(P=0.09$; Fig. $1 E)$.

\section{IL-18 mRNA expression in adipocytes}

Expression of IL-18 was confirmed by PCR. mRNA was isolated from mammary adipocyte cultures during differentiation (days 4-16). IL-18 mRNA expression could clearly be demonstrated in preadipocytes during maturation $\left(\mathrm{C}_{\mathrm{T}} 22.82 \pm 0.98 ;\right.$ mean \pm S.D. $)$. GAPDH was amplified as an mRNA quality control $\left(\mathrm{C}_{\mathrm{T}}\right.$ 21.89 $\pm 0.14 ; n=4$ in both cases).

\section{Immunocytochemistry}

Immunocytochemical experiments revealed cytoplasmatic staining for IL-18 in both preadipocytes and freshly isolated mature adipocytes (Fig. 2). The strongest staining was seen in cells with lipid droplets, which does not support the possibility that contaminating cells of the stromal fraction are responsible for IL-18 production.

\section{Discussion}

Our study demonstrates that human adipocytes release IL-18 spontaneously. Cultures of human preadipocytes secreted small but detectable amounts of IL-18 into the medium. The amounts accumulating in the supernatant during $48 \mathrm{~h}$ were increased during differentiation from preadipocytes into mature fat cells, suggesting that the ability to release IL-18 is a property already expressed in precursor cells and augmented further throughout differentiation. During the differentiation period between 45 and $55 \%$ of the initially lipidfree preadipose cells acquired the adipocyte phenotype under the adipogenic culture conditions used. It is also interesting to note that freshly isolated mature omental fat cells were found to spontaneously release IL-18 to a similar extent as in vitro-differentiated fat cells at day 12. When RNA was extracted from in vitro-differentiated adipocytes, significant amounts of IL-18 mRNA could be measured by quantitative realtime PCR, which confirmed the data from the ELISA. Using immunocytochemical methods it was possible to stain IL-18 within lipid-containing fat cells. The cytokine was found throughout the cytoplasm of adipocytes, and also around lipid droplets. These findings link the IL-18 production observed to cells of the adipocyte phenotype. Another novel and potentially important finding is that we observed a trend towards upregulation of IL-18 release in adipocyte cultures from obese compared with lean or overweight donors. Our data may help to explain why systemic IL-18 concentrations seem to correlate directly to fat cell mass. Two recent studies reported a decrease of IL-18 plasma concentrations in obese individuals upon weight loss $(9,10)$. There was a significant positive correlation between weight loss or decreased waist-to-hip ratio and low systemic IL-18 concentrations suggesting that adipose tissue might be a source of circulating IL18. IL-18 possesses a high inflammatory potency. Apart from its activity to stimulate interferon- $\gamma$ release from macrophages IL-18 exhibits marked chemoattractive properties, especially to $\mathrm{CD} 4^{+} \mathrm{T}$ cells (22). Upregulation of IL-18 release in obesity as suggested in our study 
(A)

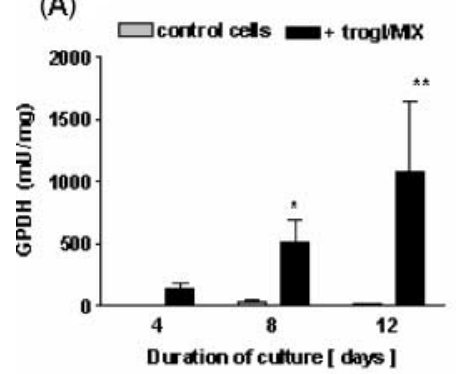

(C)

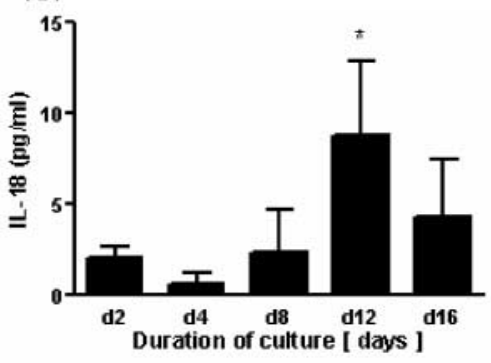

(E)

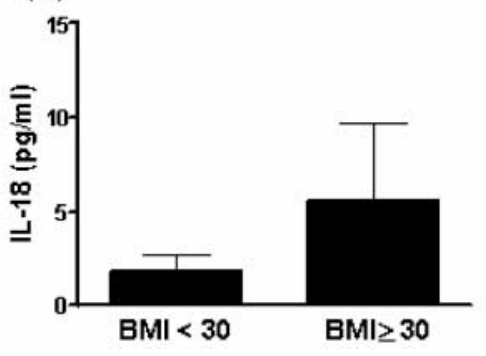

(B)

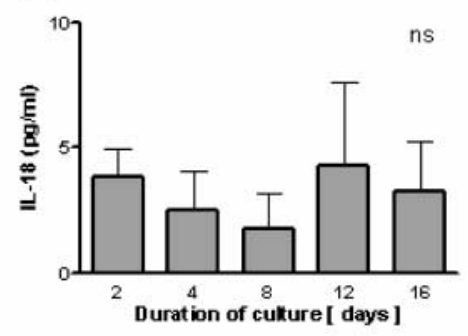

(D)

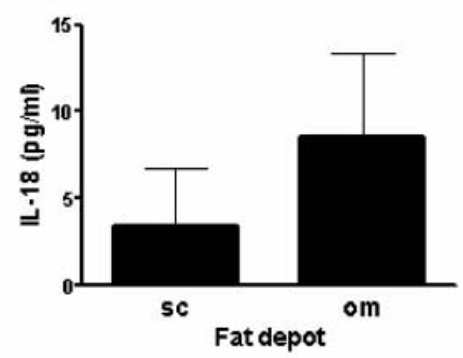

Figure 1 Adipocytes spontaneously secrete IL-18 independent of maturation stage. (A) Effect of differentiation on the development of GPDH activity in human preadipocytes from mammary adipose tissue in primary culture. Adipose differentiation was induced by addition of $0.5 \mathrm{mM}$ IBMX and $1 \mu \mathrm{g} / \mathrm{ml}$ troglitazone (trogl/MIX) for the first $72 \mathrm{~h}$ (means \pm S.D. from three experiments in duplicates; ${ }^{\star} P<0.05$, ${ }^{* \star} P<0.01$; repeatedmeasures ANOVA). (B, C) IL-18 concentrations in mammary adipose culture supernatants $48 \mathrm{~h}$ after medium exchange in the absence (B) or presence $(C)$ of troglitazone/IBMX (means \pm S.D. of cultures from three different donors; ${ }^{\star} P<0.05$, ns, not significant; repeated-measures ANOVA). (D) IL-18 concentrations in $24 \mathrm{~h}$ cultures of freshly isolated adipocytes from subcutaneous (sc) and omental (om) depots of nine and four different donors, respectively (means \pm S.D.). (E) IL-18 concentrations in 24-h cultures of freshly isolated adipocytes from subcutaneous depots from five different donors with a BMI of $<30 \mathrm{~kg} / \mathrm{m}^{2}$ and from four different donors with a BMI of $\geq 30 \mathrm{~kg} / \mathrm{m}^{2}$ (means \pm S.D.; $P=0.09$; unpaired, two-tailed $t$-test). might thus contribute to increased leukocyte infiltration into adipose tissue and to the chronic proinflammatory state in obesity. Although either Th1 or Th2 responses can be driven by IL-18, sustained IL-18 receptor expression on Th1 cells suggests a preferential activation of the latter in chronic lesions (23). IL-18 is therefore a candidate which could direct the reaction of the immune system towards a Th1-associated proinflammatory state.

It will be important to study whether adipocytes express IL-18 receptors and therefore would respond to its own product. IL-18 may also promote the detrimental effects of obesity by inducing insulin resistance in hepatocytes or muscle cells, as has been reported for other proinflammatory cytokines (24-26). A close association between systemic concentrations of IL-18 and atherogenesis is supported by reports of circulating IL-18 as a strong predictor of cardiovascular death in patients with stable and unstable angina (7). Overexpression of IL-18 was found to occur in human atheroma in situ, and due to the positive correlation between IL-18 expression and plaque instability a pathogenetic role of the cytokine atherosclerosis has been postulated (8). In animal studies based on apolipoprotein $\mathrm{E}^{-1-}$ mice, adminstration of exogenous IL-18 led to increased lesion size and augmented numbers of lesion-associated $\mathrm{T}$ cells and antigen-presenting cells (27), whereas expression of the inhibitory IL-18 binding protein or disruption of the IL-18 gene reduced progression of plaque development and destabilization $(28,29)$. There is evidence that the proatherogenic activity of IL-18 might be mediated by action on atheroma-associated endothelial cells, macrophages and smooth muscle cells, which all express the IL-18 receptor and are able respond to IL-18 stimulation $(8,30)$. In particular, incubation of human cardiac microvascular endotheial cells with IL-18 could be shown to activate proapoptotic pathways and induce endothelial cell death (31). The proatherogenic potential of IL-18 has therefore been documented by a wide range of observations, and the characterization of its cellular sources might allow for more targeted interventions in cardiovascular therapy. In summary, the data presented here demonstrate that human preadipocytes and mature adipocytes secrete IL-18. There was a trend towards higher IL-18 release from adipocytes from obese donors compared to nonobese donors. The release of IL-18 from adipose tissue may be one of the pathogenetic factors linking obesity with cardiovascular disease and other related disorders, such as type 2 diabetes. 
A

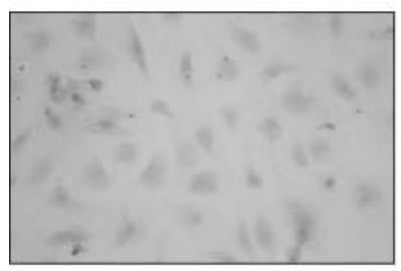

B
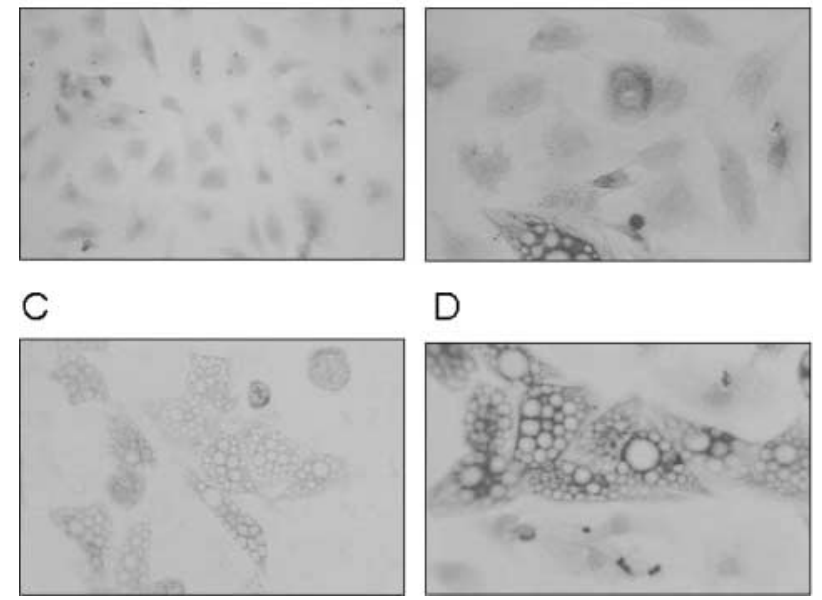

Figure 2 Expression of IL-18 protein in adipocytes from mammary adipose tissue by immunocytochemistry. (A, B) Preadipocytes without and with secondary antibody, respectively (original magnifications, $\times 20$ and $\times 40$ respectively). (C, D) Differentiated fat cells without and with secondary antibody, respectively (original magnifications, $\times 40)$. The strongest staining was seen in cells with lipid droplets.

\section{Acknowledgements}

This work was supported by the Federal Ministry of Health, the Federal Ministry of Education, Science, Research and Technology and the Ministry of School, Science and Research of the State of North Rhine-Westphalia.

\section{References}

1 Gracie JA, Robertson SE \& McInnes IB. Interleukin-18. Journal of Leukocyte Biology 200373 213-224.

2 Rothe H, Jenkins NA, Copeland NG \& Kolb H. Active stage of autoimmune diabetes is associated with the expression of a novel cytokine, IGIF, which is located near Idd2. Journal of Clinical Investigation 199799 469-474.

3 Rothe H, Hausmann A, Casteels K, Okamura H, Kurimoto M, Burkart V, Mathieu C \& Kolb H. IL-18 inhibits diabetes development in nonobese diabetic mice by counterregulation of Th1-dependent destructive insulitis. Journal of Immunology 1999163 1230-1236.

4 Liew FY. The role of innate cytokines in inflammatory response. Immunology Letters 200385 131-134.

5 Robinson DS \& O'Garra A. Further checkpoints in Th1 development. Immunity 200216 755-758.

6 Hoshino T, Kawase Y, Okamoto M, Yokota K, Yoshino K, Yamamura K, Miyazaki J, Young HA \& Oizumi K. Cutting edge: IL-18-transgenic mice: in vivo evidence of a broad role for IL-18 in modulating immune function. Journal of Immunology 2001 $667014-7018$.

7 Blankenberg S, Tiret L, Bickel C, Peetz D, Cambien F, Meyer J \& Rupprecht HJ. Interleukin-18 is a strong predictor of cardiovascular death in stable and unstable angina. Circulation 2002105 r143-r149.

8 Mallat Z, Corbaz A, Scoazec A, Besnard S, Leseche G, Chvatchko Y \& Tedgui A. Expression of interleukin-18 in human atherosclerotic plaques and relation to plaque instability. Circulation 2001 $1041598-1603$.
9 Esposito K, Pontillo A, Ciotola M, Di Palo C, Grella E, Nicoletti G \& Giugliano D. Weight loss reduces interleukin-18 levels in obese women. Journal of Clinical Endocrinology and Metabolism 2002 $873864-3866$.

10 Esposito K, Pontillo A, Di Palo C, Giugliano G, Masella M, Marfella R \& Giugliano D. Effect of weight loss and lifestyle changes on vascular inflammatory markers in obese women: a randomized trial. Journal of the American Medical Association 2003289 1799-1804.

11 Bosello O \& Zamboni M. Visceral obesity and metabolic syndrome. Obesity Reviews 20021 47-56.

12 Hauner $\mathrm{H}$. Insulin resistance and the metabolic syndrome - a challenge of the new millennium. European Journal of Clinical Nutrition 200256 (Suppl 1) S25-S29.

13 Kershaw EE \& Flier JS. Adipose tissue as an endocrine organ. Journal of Clinical Endocrinology and Metabolism $2004 \mathbf{8 9}$ 2548-2556.

14 Weisberg SP, McCann D, Desai M, Rosenbaum M, Leibel RL \& Ferrante AW. Obesity is associated with macrophage accumulation in adipose tissue. Journal of Clinical Investigation 2003 112 1796-1808.

15 Xu H, Barnes GT, Yang Q, Tan G, Yang D, Chou CJ, Sole J, Nichols A, Ross JS, Tartaglia LA \& Chen H. Chronic inflammation in fat plays a crucial role in the development of obesity-related insulin resistance. Journal of Clinical Investigation 2003112 1821-1830.

16 Bastard JP, Jardel C, Bruckert E, Blondy P, Capeau J, Laville M, Vidal H \& Hainque B. Elevated levels of interleukin 6 are reduced in serum and subcutaneous adipose tissue of obese women after weight loss. Journal of Clinical Endocrinology and Metabolism $2000853338-3342$.

17 Ziccardi P, Nappo F, Giugliano G, Esposito K, Marfella R, Cioffi M, D'Andrea F, Molinari AM \& Giugliano D. Reduction of inflammatory cytokine concentrations and improvement of endothelial functions in obese women after weight loss over one year. Circulation $2002105804-809$.

18 Giugliano G, Nicoletti G, Grella E, Giugliano F, Esposito K, Scuderi N \& D'Andrea F. Effect of liposuction on insulin resistance and vascular inflammatory markers in obese women. British Journal of Plastic Surgery 200457 190-194.

19 Hauner H, Skurk T \& Wabitsch M. Cultures of human adipose precursor cells. Methods in Molecular Biology $2001 \quad 155$ $239-247$.

20 Pairault J \& Green H. A study of the adipose conversion of suspended 3T3 cells by using glycerophosphate dehydrogenase as differentiation marker. PNAS $197965138-5142$.

21 Lowry OH, Rosebrough NJ, Farr AL \& Randall RJ. Protein measurement with the folin-phenol reagents. Journal of Biological Chemistry 1951195 265-275.

22 Komai-Koma M, Gracie JA, Wei XQ, Xu D, Thomson N, McInnes IB \& Liew FY. Chemoattraction of human T cells by IL-18. Journal of Immunology $2003 \mathbf{1 7 0} 1084-1090$.

23 Gracie JA, Forsey RJ, Chan WL, Gilmour A, Leung BP, Greer MR, Kennedy K, Carter R, Wei XQ, Xu D, Field M et al. A proinflammatory role for IL-18 in rheumatoid arthritis. Journal of Clinical Investigation $1999 \mathbf{1 0 4} 1393-1401$.

24 Grimble RF. Inflammatory status and insulin resistance. Current Opinion in Clinical Nutrition and Metabolic Care 20025 551-559.

25 Das UN. Is obesity an inflammatory condition? Nutrition $2001 \mathbf{1 7}$ 953-966.

26 Whitman SC, Ravisankar P \& Daugherty A. Interleukin-18 enhances atherosclerosis in apoliopoprotein $\mathrm{E}^{-1-}$ mice through release of interferon- $\gamma$. Circulation Research 200290 E34-E38.

27 Greenberg AS \& McDaniel ML. Identifying the links between obesity, insulin resistance and beta-cell function: potential role of adipocyte-derived cytokines in the pathogenesis of type 2 diabetes. European Journal of Clinical Investigation 200232 (Suppl 3) $24-34$. 
28 Mallat Z, Corbaz A, Scoazec A, Graber P, Alouani S, Esposito B, Humbert Y, Chvatchko Y \& Tedgui A. Interleukin-18/interleukin-18 binding protein signaling modulates atherosclerotic lesion development and stability. Circulation Research 200189 E41-E45.

29 Elhage R, Jawien J, Rudling M, Ljunggren HG, Takeda K, Akira S Bayard F \& Hansson GK. Reduced atherosclerosis in interleukin18 deficient apolipoprotein E-knockout mice. Cardiovascular Research $200359234-240$.

30 Gerdes N, Sukhova GK, Libby P, Reynolds RS, Young JL \& Schönbeck U. Expression of interleukin (IL)-18 and functional IL-18 receptor on human vascular endothelial cells, smooth muscle cells, and macrophages: implications for atherogenesis. Journal of Experimental Medicine 2002195 245-257.

31 Chandrasekar B, Vemula K, Surabhi RM, Li-Weber M, OwenSchaub LB, Jensen LE \& Mummidi S. Activation of intrinsic and extrinsic proapoptotic signaling in interleukin-18-mediated human cardiac endothelial cell death. Journal of Biological Chemistry $200427920221-20233$.

Received 18 November 2004

Accepted 26 January 2005 